\title{
Alopecia por diluição da cor em uma cadela Staffordshire Bull Terrier azul: Relato
}

\section{de caso}

\author{
Color dilution alopecia in a blue Staffordshire Bull Terrier bitch: Case report \\ Alopecia por dilución de color en un Staffordshire Bull Terrier azul: Reporte de caso
}

Recebido: 02/03/2021 | Revisado: 10/03/2021 | Aceito: 14/03/2021 | Publicado: 21/03/2021

Durval Baraúna Júnior

ORCID: https://orcid.org/0000-0002-0261-6672 Universidade Federal do Vale do São Francisco, Brasil

E-mail: durvalbarauna@hotmail.com

Ana Catarina Luscher Albinati

ORCID: https://orcid.org/0000-0003-2954-3431 Universidade Federal do Vale do São Francisco, Brasil E-mail: catarina.albinati@gmail.com

Angélica Liberalino da Silva

ORCID: https://orcid.org/0000-0003-0470-4323 Universidade Federal do Vale do São Francisco, Brasil

E-mail: angelica.liberalino@gmail.com

José Guilherme Xavier

ORCID: https://orcid.org/0000-0001-8476-1306

Universidade Paulista, Brasil

E-mail: xavier2126@gmail.com

Mario José dos Santos Júnior

ORCID: https://orcid.org/0000-0003-1002-4017

Laboratório ROUS, Brasil.

E-mail: mario@ rous.com.br

\begin{abstract}
Resumo
Em cães a alopecia por diluição da cor (ADC) é uma das afecções dermatológicas que leva a gradual perda dos pelos em animais que possuem pelagens diluídas, como a azul. Embora relativamente rara, a ADC foi observada em diversas raças. Descreve-se aqui um caso em uma cadela de pelagem azul da raça Staffordshire Bull Terrier, atendida em um hospital veterinário de Pernambuco, Brasil. A cadela apresentava rarefação dos pelos desde os seis meses de idade, e ao exame clinico foi observada alopecia no dorso e flanco. Exames complementares foram requisitados e feitos para descartar outros diagnósticos em potencial tais como infeções parasitárias da pele e doenças de origem endócrina. Realizou-se uma biópsia da pele para avaliação histopatológica, onde foi possível observar a presença de plugs de melanina nos folículos pilosos, distorção posterior dos mesmos, pigmentação adjacente aos folículos e a presença de melanógafos, alterações que sugeriram ADC. Através do resultado do exame histopatológico associado aos sinais clínicos e o histórico do animal, foi possível confirmar o diagnóstico de alopecia por diluição da cor. Não foi realizado tratamento terapêutico nesse caso, tendo em vista que os tratamentos existentes variam em resultado e o tutor optou pela não realização do mesmo.
\end{abstract}

Palavras-chave: ADC; Cães; Dermatologia veterinária.

\begin{abstract}
In dogs, color dilution alopecia (CDA) is one of the skin conditions that leads to progressive hair loss in animals with color diluted coat, such as blue. Although relatively rare, color dilution alopecia has already been described in many races. Here, we describe a case in a blue Staffordshire Bull Terrier bitch, attended in a veterinary hospital in Pernambuco, Brazil. The bitch presented hair rarefaction since it was six months old, at medical examination it was possible to observe alopecia in the dog's back and flank. Additional tests were performed, discarding other potential diagnosis such as parasitic infections and endocrinal diseases. Then, a skin biopsy was performed to proceed with histopathological evaluation, where it was possible to observe melanin plugs in the hair follicles, causing the distortion of said follicles, pigmentation in the near regions and the presence of melanophages, alterations that suggested CDA. Through the results of the histopathological analysis, associated with the clinical signs and the animal's historic, it was possible to reach the diagnosis of color dilution alopecia. No treatment was instituted, taking into consideration that the efficacy of the existing treatments varies and the tutor decided against it.
\end{abstract}

Keywords: CDA; Dogs; Veterinary dermatology. 


\begin{abstract}
Resumen
En los perros, la alopecia por dilución del color (ADC) es una de las afecciones dermatológicas que conduce a la pérdida gradual de pelo en animales que tienen el pelaje diluido, como el azul. Aunque es relativamente raro, se ha observado ADC en varias razas. Aquí se describe un caso en un perro de pelo azul de la raza Staffordshire Bull Terrier, visto en un hospital veterinario en Pernambuco, Brasil. La perra presentaba escasez de pelo desde los seis meses y el examen clínico reveló alopecia en el lomo y el flanco. Se solicitaron y realizaron pruebas complementarias para descartar otros posibles diagnósticos como infecciones parasitarias de la piel y enfermedades de origen endocrino. Se realizó biopsia de piel para evaluación histopatológica, donde se pudo observar la presencia de tapones de melanina en los folículos pilosos, distorsión posterior de los mismos, pigmentación adyacente a los folículos y presencia de melanogafes, cambios que sugirieron ADC. A través del resultado del examen histopatológico asociado a los signos clínicos y la historia del animal, fue posible confirmar el diagnóstico de alopecia por dilución del color. En este caso no se realizó tratamiento terapéutico, considerando que los tratamientos existentes varían en consecuencia y el tutor optó por no hacerlo.
\end{abstract}

Palabras clave: ADC; Dermatología veterinaria; Perros.

\title{
1. Introdução
}

Alopecia é o nome dado a afecções cutâneas caracterizadas pela redução ou ausência de pelos na pele, pode ser classificada como uma enfermidade inflamatória crônica dos folículos pilosos (Macedo, et al., 2020).

A alopecia por diluição de cor (ADC) é uma enfermidade rara que afeta a camada ectodérmica e tem origem genética (Gouveia, et al., 2020), levando a alopecia parcial em animais com pelagens de cores diluídas a partir de cores base (Perego, et al., 2009; Santos, et al. 2017), tais como o "azul" derivado de cinza e preto (Ferreira, et al. 2007; Palumbo, et al., 2012).

Os animais não manifestam a doença ao nascimento, a alopecia tem início entre os 4 e 18 meses de idade, em raros casos sendo observada em animais mais velhos entre 3 e 6 anos (Perego, et al., 2009). Os sinais principais são a característica hipotricose gradual (Palumbo, et al., 2012), alopecia das áreas de coloração diluída, pelos de má qualidade e de coloração opaca, fraturados e suscetíveis a queda ao toque (Perego, et al., 2009). Na maioria dos casos a alopecia é mais intensa no dorso, poucas vezes alcançando os membros, cauda e cabeça. Contudo, esse padrão de distribuição varia entre raças (Kim, et al., 2005). Em alguns casos a pele pode apresentar intensa descamação e prurido, decorrente de infecções bacterianas secundárias (Ferreira, et al., 2007).

Os mecanismos que facilitam a ocorrência de ADC ainda não estão completamente elucidados (Kim, et al., 2005). No entanto, sabe-se que há uma relação entre o desencadeamento dessa enfermidade e um fator genético, sendo a alopecia por diluição de cor uma doença autossômica recessiva ligada a genes que definem a coloração de pelagem do animal e afetam o folículo piloso (Ferreira, et al., 2007; Palumbo, et al., 2012). Não há predisposição de sexo para esta condição, afetando machos e fêmeas com a mesma frequência. Já foi observada em diversas raças, tais como Boiadeiro de Berna, Chow Chow, Chihuahua, Doberman Pinscher, Dachshund, Galgo Italiano, Yorkshire Terrier, Schnauzer, Setter Irlandês, Poodle, Saluki e Whippet, sendo rara em animais sem raça definida (Perego, et al., 2009).

Esse trabalho relata um caso de alopecia por diluição em uma cadela Staffordshire Bull Terrier de pelagem azul atendida em um centro médico veterinário de Pernambuco.

\section{Metodologia}

Este artigo é um estudo de caso único, é um estudo qualitativo e descritivo, de acordo Pereira et al. (2018) caracterizase como uma pesquisa que de forma direta colhe dados relativos ao caso através do acesso aos registros médicos e aos exames fornecidos, sendo o pesquisador o instrumento primordial.

No presente estudo, foi realizada a da coleta de dados registrados em prontuários médicos fornecidos pelos autores envolvidos no caso e com autorização do responsável pelo animal. Foi feita a avaliação do histórico do animal, assim como dos exames clínicos e exames complementares. Foi consultada literatura relevante, em bancos de dados como Pubvet e 
CAPES, realizando uma análise dos artigos relevantes ao tema do estudo.

\section{Descrição de Caso}

Uma cadela de 3 anos de idade da raça Staffordshire Bull Terrier de pelagem "azul" foi recebida em um hospital veterinário para avaliação dermatológica. O animal possuía histórico de rarefação dos pelos desde os 6 meses de idade. À avaliação física foi possível observar pelos ressecados, hipotricose generalizada, alopecia bilateral em dorso, flanco e cauda, sem presença de prurido ou ectoparasitas (Figura 1). Os parâmetros vitais do animal se encontravam normais. Não foram observadas quaisquer outras anormalidades.

Figura 1. Vista superior do dorso do cão. Setas brancas apontam para as áreas de coloração diluída, apresentando rarefação capilar e alopecia em estágio inicial.

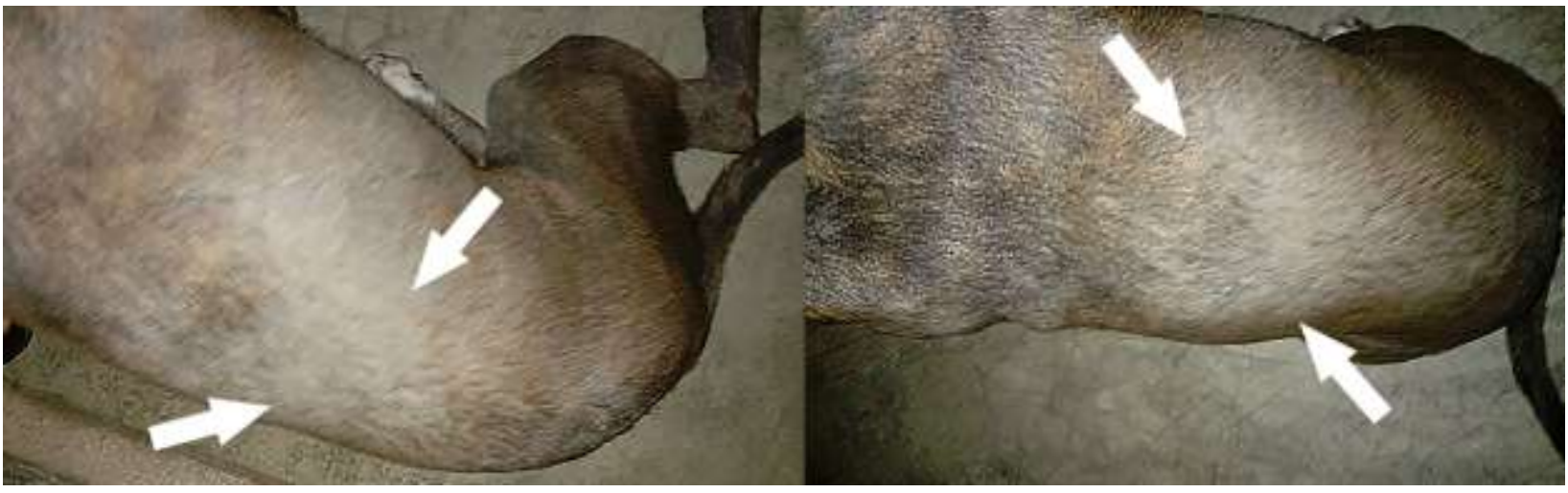

Fonte: Autores.

Exames complementares foram realizados para se chegar a um diagnóstico. Foi realizada coleta de amostras para tricograma, contudo o resultado foi inconclusivo. O raspado cutâneo teve resultado negativo para infecções por parasitas e fungos, assim como outros patógenos. Foram também verificados os níveis séricos de T4 do animal, estes se encontravam dentro da faixa de normalidade para a espécie $(1,9 \mu \mathrm{g} / \mathrm{dL})$.

A biópsia de pele foi conduzida com material coletado na base da cauda do animal, sendo realizada então avaliação histopatológica da amostra. No exame histopatalógico foram observados plugs de melanina na extensão dos folículos pilosos com eventual distorção dos mesmos (Figura 2A), pigmentação dos sítios adjacentes aos folículos e presença de melanófagos alcançando o tecido subcutâneo (Figura 2B), assim como vacuolização discreta dos miócitos presentes nos músculos eretores do pelo. O diagnóstico era compatível com alopecia por diluição da cor (alopecia do mutante de cor). 
Figura 2. Cortes histológicos da pele. A. Presença de limites foliculares tortuosos e frequentes agregados de melanina ao longo do folículo piloso (HE, 10x). B. Pigmentação de cercanias foliculares, associada a melanófagos, alcançando tecido subcutâneo (HE, 40x.).



Fonte: Autores.

Após alcançado diagnóstico conclusivo, o proprietário optou por não realizar tratamento, tendo em vista que a eficácia do tratamento é variável e a condição não afetava o estado de saúde do animal, apenas seu aspecto estético.

\section{Discussão}

Colorações de pelagem diluídas são frequentes em diversas raças. A cor está relacionada a pigmentação de eumelanina e feomelanina que confere colorações pálidas que variam conforme a raça, podendo variar entre diversas cores (Schmutz \& Berryere, 2007; Gouveia, et al., 2020), tais como azul e cinza. A coloração diluída é herdada de forma recessiva autossômica, por conta de mutações no gene MLPH também encontrado em outras espécies (Welle, et al., 2009).

Não se chegou a um consenso sobre o mecanismo que leva a ocorrência alopecia por diluição de cor (Miller, 1991; Kim, et al., 2005). Atualmente, sabe-se apenas que a origem da alopecia por diluição é relacionada à ocorrência de mutações no gene MLPH (Perego, et al., 2009). As proteínas codificadas pelo MLPH, assim como por MYO5A e RAB27A são de suma importância na pigmentação granular, atuando na distribuição, transporte e translocação de pigmentos (Santos, et al., 2017).

Schmutz e Berryere (2007) em um estudo com mais de 20 raças diferentes, observaram que cerca de $25 \%$ dos animais com pelagem de coloração diluída apresentaram a ADC, Animais homozigotos para alelos mutantes do gene MLPH foram mais acometidos, contudo animais heterozigotos apresentaram a doença com menor frequência. Indicando que animais de coloração diluída, tais como a azul, são mais predispostos à ocorrência de alopecia por diluição da cor.

Welle et al. (2009) e Santos et al. (2017) em seus respectivos trabalhos descreveram a ocorrência ADC em cães em decorrência de uma mutação pontual no exon 1 do gene MLPH, essa mutação denominada SNP c. $-22 \mathrm{G}>\mathrm{A}$ é resultante do pleomorfismo de um único nucleotídeo. Em estudos mais recentes, Bauer et al. (2017) identificou outra variante dentro do gene MLPH, a c.705G>C, como possível responsável pela expressão da diluição de cor em cães da raça Chow Chow, contudo não há estudos relativos à influência dessa variante na ocorrência de alopecia.

Não foram encontrados testes genéticos comerciais para o diagnóstico definitivo da ADC, como acreditasse que o fator genético é para a doença (Perego, et al., 2009; Santos, et al., 2017; Gouveia, et al., 2020) é de extrema importância no plano de criação, a retirada da reprodução de portadores da doença e a realização de acasalamentos que evitem o nascimento de cães diluídos, até que o completo mecanismo da doença esteja esclarecido.

Para o diagnóstico clinico da alopecia por diluição da cor as técnicas mais comuns consistem na avaliação do histórico 
do animal, sinais clínicos, análise genética e principalmente pela análise microscópica dos pelos e exames histopatológicos (Lopes, et al., 2017). Primeiramente, à análise do histórico clínico do animal identificou-se que o inicio do quadro se deu dentro da faixa etária esperada em animais com ADC, que é entre 4 a 18 meses de vida (Perego, et al., 2009), assim como sua evolução gradual e os sinais clínicos característicos, como hipotricose e baixa qualidade dos pelos, eram compatíveis com a suspeita.

Segundo Kim et al. (2005) e Ferreira et al. (2007) deve-se levar em consideração o caráter raro da alopecia por diluição da cor, sendo necessária a exclusão de todas as demais causas de alopecia, como enfermidades dermatológicas de origem microbiana e endócrina. A realização do diagnóstico diferencial foi feita através da realização de exames complementares previamente descritos. O raspado cutâneo teve resultado negativo para a presença de demodex e outros agentes patogênicos, excluindo a suspeita de origem infecciosa.

A displasia folicular do pelo preto é o diagnóstico diferencial mais comum, dada a similaridade das duas doenças na análise histopatológica (Aléssio, et al., 2020; Gondim \& Araujo, 2020), contudo o animal não apresentava pelagem de tal cor, eliminando essa possiblidade sumariamente.

Hargis et al. (1977) e Welle et al. (2009) relatam que desordens de etiologia endócrina, como o hipotireoidismo, podem apresentar quadro clinico semelhante, portanto, devem ser consideradas como diagnósticos diferenciais. Dessa forma, foi realizada a dosagem de T4 livre, obtendo-se resultados dentro da faixa de normalidade, descartando a possibilidade de origem endócrina para a alopecia.

A análise histopatológica mostrou-se essencial para o diagnóstico definitivo da alopecia por diluição da cor. Isso está de acordo com a literatura, onde Ferreira et al. (2007) afirma que a análise microscópica pode confirmar o diagnóstico. Ao exame histopatológico foram visualizadas alterações compatíveis com o previamente descrito na literatura por autores como Welle et al. (2009) e Lopes et al. (2017) que relataram que a confirmação do diagnóstico se dá através da visualização de macromelanossomas espalhados desordenadamente ao longo dos fios, hiperqueratose epidérmica, melanófagos com o acúmulo de melanina tornando os pelos mais frágeis, propensos a fraturas no momento que emergem do folículo piloso. Essas alterações associadas ao quadro clinico e ao histórico do animal, tornaram possível confirmar a ADC na cadela.

Antibioticoterapia associada a tratamento paliativo a descamação da pele, pode ser realizada quando há foliculite bacteriana secundária a alopecia, visando reduzir a descamação e o prurido (Lopes, et al., 2017), todavia, isso não foi pertinente ao caso. Recomendou-se o uso de xampus ceratomodulares, emolientes e antissépticos para minimizar a queratinização das regiões afetadas, seguindo protocolo sugerido por Miller (1991). Embora alguns autores recomendem o uso de melatonina para auxiliar a repilação parcial dos animais (Kim, et al., 2005), Perego et al. (2009) relatou que o uso de melatonina não favoreceu a reversão do quadro, logo essa terapia não foi realizada nesse caso.

\section{Considerações Finais}

A alopecia por diluição da cor é uma enfermidade que afeta cães de várias raças com pelagem de cor diluída, incluindo animais da raça Staffordshire Bull Terrier. São necessários mais estudos, principalmente focados no aspecto genético, para o melhor entendimento da expressão dessa doença. Desta forma possibilitando aos médicos veterinários e criadores uma seleção adequada nos programas de acasalamento, no intuito de minimizar a ocorrência da doença.

\section{Referências}

Aléssio, B. C., Braga, D., Palumbo, M. I. P. \& Babo-Terra, V. J. (2020). Black hair follicular dysplasia in a fox paulistinha dog: clinical and histopathological features. Acta Veterinaria Brasilica, 12, 136-139. 10. 21708/avb. 2020. 14. 3. 9010

Bauer, A., Kehl, A., Jagannathan, V. \& Leeb, (2017). T. A novel MLPH variant in dogs with coat colour dilution. Animal Genetics, 49, 94-97. 10. 1111/age. 12632 
Research, Society and Development, v. 10, n. 3, e43710313486, 2021

(CC BY 4.0) | ISSN 2525-3409 | DOI: http://dx.doi.org/10.33448/rsd-v10i3.13486

Ferreira, R. R., Machado, M. L. S., Aguiar, J. \& Spanamberg, A. (2007). Displasias foliculares ligadas à cor da pelagem em cães: displasia folicular dos pelos pretos e alopecia por diluição da cor. Acta Scientiae Veterinariae, 35, 119-124. 10. 22456/1679-9216. 15934

Gondim, A. L. C. L. \& Araujo, A. K. L. (2020). Displasia folicular dos pelos pretos em cães: Revisão. Pubvet, 14(4), 1-6.

Gouveia, M. C. S., Mencalha, R. N. \& Mourão, M. I. O. C. (2020). Alopecia por diluição da cor em cão da raça yorkshire: relato de caso. Pubvet, 14(2), 1-4. 10. 31533/pubvet. v14n2a509. 1-4

Hargis, A. M., Thomassen, R. W. \& Phemister, R. D. (1977). Chronic dermatosis and cutaneous squamous cell carcinoma in the Beagle dog. Veterinary Pathology, 14, 218-28. 10. 1177/030098587701400304

Kim, J. H., Kang, K. I., Sohn, H. J., Woo, G. H., Jean, Y. H. \& Hwang, E. K. (2005). Color-dilution alopecia in dogs. Journal of Veterinary Science, 3(6), 259261.

Lopes, N. L., Peixoto, A. P., Costa, T. S., Pisani, R. B. R., Medeiros, C. M. B. T., Ramadinha, R. R., Mascarenhas, M. B. \& Fernandes, J. I. (2017). Alopecia por diluição da cor: relato de caso. Brazilian Journal of Veterinary Medicine, 3(39), 198-202. 10. 29374/2527-2179. bjvm014117

Macedo, C. L. A., Santana, T. S., Ferreira, A. F. P., Jucá, N. B. H., Crispim, K. S. L., Banhos, M. E. H., Amorim, L. C. P., Rabelo, K. P. S., Brasil, D. R. M., Basso, S., Araújo, R. C., Rios, M. S., Costa, A. J. A. \& Castro júnior, J. E. (2020). Androgenetic alopecia (New capillary protocol in androgenic alopecia). Research, Society and Development, 9(9), 1-23. 10.33448/rsd-v9i9. 7457

Miller, W. H. (1991). Alopecia associated with coat colour dilution in two Yorshire Terriers, one Saluki and one mix-breed. Journal of the American Animal Hospital Association, 27, 39-43.

Palumbo, M. I. P., Fabris, V. E. \& Machado, L. H. A. (2012). Carcinoma de células escamosas em um cão com alopecia por diluição de cor. Veterinária e Zootecnia, 4(19), 507-512.

Perego, R., Proverbio, D., Roccabianca, P. \& Spada, E. (2009). Color dilution alopecia in a blue Doberman pinscher crossbreed. Canine Veterinary Journal, 50: 511-514.

Pereira, A. S., Shitsuka, D. M., Parreira, F. J. \& Shitsuka, R. (2018). Metodologia da pesquisa científica. UFSM.

Santos, L. M., Messas, N. B., Palumbo, M. I. P., Miyasato, L. A., Leal, P. V., Martins, T. B. \& Ramos, C. A. N. (2017). Identification of SNP c. -22G>A in the melanophilin gene from a dog with color dilution alopecia: case report. Arquivo Brasileiro de Medicina Veterinária e Zootecnia, 6(69), 1503-1507. 10. $1590 / 1678-4162-9710$

Schmutz, S. M. \& Berryere, T. G. (2007). Genes affecting coat colour and pattern in domestic dogs: a review. Animal Genetics, 38, 539-549. 10. 1111/j. 13652052. 2007. 01664. x

Welle, M., Phillipp, U., Rüfenacht, S., Roose, P., Scharfenstein, M., Schütz, E., Brenig, B., Linek, M., Mecklenburg, L., Grest, P., Drögemüller, M., Haase, B., Leeb, T. \& Drögemüller C. (2009). MLPH genotype-Melanin phenotype correlation in Dilute Dogs. Journal of Heredity, 100, 75-79. 10. 1093/jhered/esp010 